\title{
Mini review: interactions between antifungal azoles, neurological bladder and urinary problems
}

\author{
Nadia Bounoua', Nadjib Mohamed Rebizi ${ }^{2}$ \\ University of Tahri Mohamed, Bechar, Algeria \\ ${ }^{1}$ Corresponding author \\ E-mail: ${ }^{1}$ bounoua_nadia@yahoo.fr, ${ }^{2}$ rebizi-nadjib@hotmail.fr \\ Received 15 August 2019; accepted 10 October 2019 \\ DOI https://doi.org/10.21595/chs.2019.20951
}

Check for updates

Copyright (C) 2019 Nadia Bounoua, et al. This is an open access article distributed under the Creative Commons Attribution License, which permits unrestricted use, distribution, and reproduction in any medium, provided the original work is properly cited.

\begin{abstract}
This review describes the importance of antifungal drugs in medicinal, pharmaceutical and agriculture fields because of their wide spectrum of biological activities in the recent years. Their chemical structure has expected considerable interest. Also, we focus on urinary problems and can be helpful to develop the ideas in neurological bladder for see the interactions and effect of antifungal drugs in system neurologic, because urinary tract infection is one of the most frequent diseases in medical practice. Some definitions are discussed and reported emphasizing microbiological, clinical and therapeutic aspects.
\end{abstract}

Keywords: antifungal drugs, azole, urinary tract, infection, neurological bladder.

\section{Introduction}

The past decade has witnessed a significant increase in the prevalence of resistance to antibacterial and antifungal agents. Resistance to antimicrobial agents has important implications for morbidity, mortality and health care costs in U.S. hospitals, as well as in the community $[1,2]$. Hence, substantial attention has been focused on developing a more detailed understanding of the mechanisms of antimicrobial resistance, improved methods to detect resistance when it occurs, new antimicrobial options for the treatment of infections caused by resistant organisms, and methods to prevent the emergence and spread of resistance in the first place [2].

Urinary tract infection is one of the most frequent infectious diseases in medical practice. More than 7 million episodes of acute cystitis are estimated to occur in the United States every year [3]. They including bacteriuria in patients with indwelling catheters, are the leading nosocomial infections, mainly in elderly patients [4]. Add to this diabetes mellitus, urinary tract abnormalities such as neurogenic bladder and obstruction, and malignancy.

The study of resistance to antifungal agents has lagged behind that of antibacterial resistance for several reasons. Perhaps most importantly, fungal diseases were not recognized as important pathogens until relatively recently $[5,6]$. Therapeutic science and specially in chemistry is the control worried about deciding the impact and effect of substance structure on natural action and in the act of restorative science created from an observational one including the natural combination of another new compound dependent on the adjustment of structure and after that recognizes their organic action $[7,8]$.

The pharmaceutical chemistry heed with the disclosure, improvement, elucidation and the recognizable proof and mechanism of action of each component and their biological activity at the sub-atomic level [9]. Different biologically active synthetic compounds have a five-membered nitrogen-containing heterocyclic ring in their structures [10].

Basic systems structure has been portrayed as advantaged structures and specifically, $\mathrm{N}$-containing polycyclic structures have been accounted for to be related with a wide scope of organic and biological action. In the field of five-membered heterocyclic structures, imidazole core demonstrates different properties. The high helpful properties of the imidazole related medications have urged the restorative scientists and chemists to blend countless novel chemotherapeutic operators. Imidazole drugs have expanded extension in helping different auras 
in clinical prescriptions $[11,12]$. This family presents in azoles antifungal which prevents the gathering of methylated sterols damage the synthesis of the lipid bilayer of membranes.

Some imidazole drugs, at high concentrations, could apply a direct inhibitory activity on membranes, without involvement with sterols and sterol esters [13, 14].

Imidazole and its derivatives are reported to be physiologically and pharmacologically active and discovery applications in in the treatment of a few illnesses. The fact that the increase in the incidence of worldwide fungal infections and emergence of antifungal drug resistance which outcompetes the development of novel antifungal compounds, it becomes important to understand the various facets of infections and to understand the basic mechanisms that govern the development of resistance. This enforces the widening of the hunt for the development of new antifungals targeting novel pathways. This review focuses on some of the aspects of antifungals, their interactions between antifungal azoles and neurological bladder problems.

\subsection{Antifungal drugs and some urinary problem}

Human mycoses can be categorized as superficial, 1ocalized, or disseminated. Superficial mycoses are generally confined to the skin and nails, whereas localized mycoses include infections of the gastrointestinal, genitourinary, and respiratory tracts. Disseminated, or deep, mycoses are characterized by fungal infections of the visceral organs, central nervous system (CNS), and/or generalized fungal septicemia $[13,14]$. While the superficial infections can be a source of great discomfort, they are not life threatening and are generally treatable with a variety of topical (or, in the same cases, oral) antifungal agents $[15,16]$. Currently only four clinically useful antifungal agents are indicated for the treatment of systemic mycoses and that selectively eliminates fungal pathogens from a host with minimal toxicity to the host. These fall into three structural classes (polyene antibiotics, ftucytosine, and synthetic azoles) with three different molecular targets $[17,18]$.

The majority of people experience some or all of these symptoms if they have a urinary tract infection. Symptoms of a UTI can be confused with other MS symptoms such as fatigue or existing bladder problems. Urine infections are straightforward to treat but if left untreated they can be a trigger for spasticity or cause a relapse.

In the system human, the ordinary function of the urinary bladder is to stock and expel urine in a coordinated, controlled fashion. This coordinated activity is regulated by the central and peripheral nervous systems [1].

For the neurological bladder the wrong is when several muscles and nerves must work together for your bladder to hold urine until you are ready to empty it.

Nerve messages go back and forth between the brain and the muscles that control bladder emptying. If these nerves are damaged by illness or injury, the muscles may not be able to tighten or relax at the right time. In people with neurogenic bladder, the nerves and muscles don't work together well. The bladder may not fill or empty in the right way. So, on general when the nerve damage causes bladder problems.

This lower urinary tract brokenness coming about because of spinal rope damage (SCI) is as yet in charge of high morbidity, and for annoyance, for example; urinary incontinence frequently becomes to the patient's social actives. Adequate urological care is a significant section of the difficult strategies and intricate treatment of the spinal cord harmed. Expanding knowledge with various treatment methodologies, created during the most recent 10 years in the field of neuro-urology, legitimizes an update of current helpful ideas.

\subsection{Types of neurogenic bladder dysfunction}

In this part, we discuss in the various types of the neurologic bladder and especially the operation, where the assignments of the urinary bladder muscle and its sphincters, the accumulation of urine with upkeep of urinary self-control, which suggests the ability of the 
detrusor to unwind and of the sphincter mechanism to keep up the bladder outlet shut even with an abrupt increment of intra-abdominal pressure, and the discharging of the bladder voluntarily, without remaining pee, which infers the ability of the detrusor to contract and of the sphincter to unwind all the while [20].

This synergistic activity is essential for complete discharging with a physiological intravesical compression. Harm to the innervation of the lower urinary tract, for the most part, influences both the detrusor and the sphincter. For any helpful curative thought, the assessment of the detrusor and the sphincter is fundamental [21].

\subsection{Biological activity of antifungal drugs}

\subsubsection{Biological activity of imidazoles}

In this section of the different biological activities of antifungal drugs Fig. 1. Imidazole and its derivatives are described to be physiologically and pharmacologically dynamic and detect applications in the treatment of a few maladies. Furthermore, they have a significant advantage of an assortment of medicinal operators $[13,14]$. Based on different writing studies, imidazole derivatives show different pharmacological activities.<smiles>OC(Cn1cncn1)(Cn1cncn1)c1ccc(F)cc1F</smiles><smiles>Clc1ccc(COC(Cn2ccnc2)c2ccc(Cl)cc2Cl)c(Cl)c1</smiles><smiles>Clc1ccc(C(Cn2cccn2)OCc2csc3c(Cl)cccc23)c(Cl)c1</smiles><smiles>Clc1ccc(C(Cn2ccnc2)OCc2ccsc2Cl)c(Cl)c1</smiles><smiles>N#CC(=C1SC[C@H](c2ccc(Cl)cc2Cl)S1)n1ccnc1</smiles>
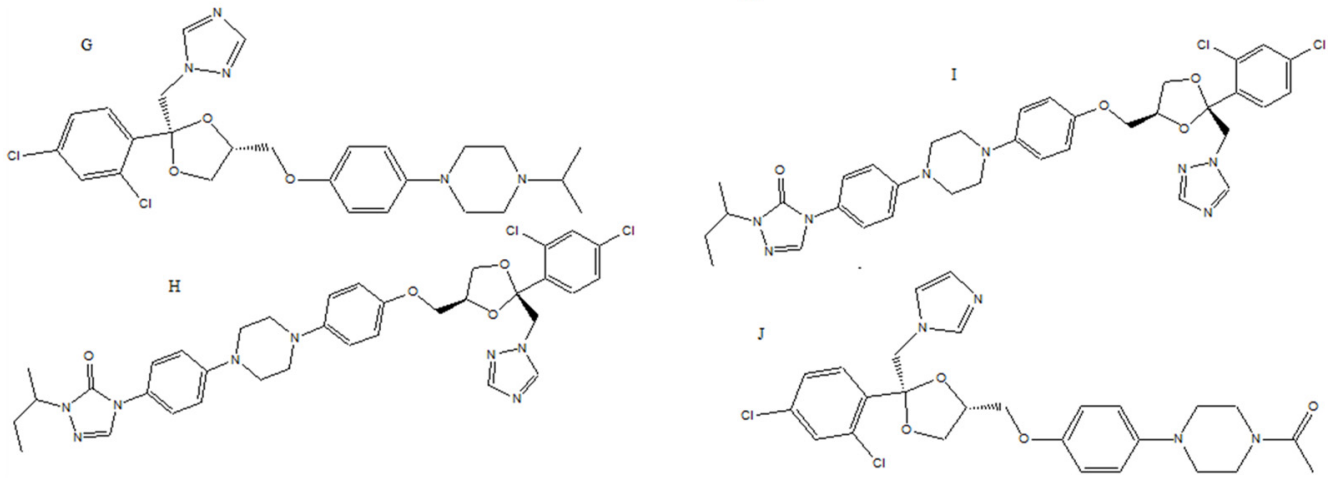

Fig. 1. Some structures of antifungal drugs

\subsubsection{Antifungal and antibacterial activity}

Ramya V. created a chain of novel 5-(nitro/Bromo)-styryl-2-benzimidazole derivatives and examined for the antibacterial activity versus Staphylococcus aureus, Escherichia coli, Enterococcus faecalis, and Klebsiella pneumonia and hostile to parasitic action versus Candida albicans and Aspergillus disinfect. This was practically identical and similar with ciprofloxacin [22]. 


\subsubsection{Anti-inflammatory and analgesic activities}

Puratchikody A. Research and examines on 2-substituted-4, 5-diphenyl-1H-imidazoles and tested the anti-inflammatory activity dependent on Carrageenan-prompted paw edema strategy. This compound shows the most extreme movement and indomethacin utilized as reference drug [23].

\subsubsection{Anti-tubercular activity}

Ramya V. created series of novel 5-(nitro/bromo)-styryl-2-benzimidazoles (1-12) derivatives and selected for test in vitro anti-tubercular activity contrary to Mycobacterium tuberculosis, and these mixtures presented good antitubercular activities [22].

\subsubsection{Anti-depressant activity}

Farzin Hadizadeh et al. produced moclobemide analogues by substituting moclobemide phenyl ring with exchanged imidazole and studied for the antidepressant activity with forced swimming test. Analogues $7 \mathrm{a}-\mathrm{c}$ was created to be further strong than moclobemide [24].

\subsubsection{Anti-cancer activity}

Yusuf Ozkay produced several novel imidazole-(Benz) azole and imidazole epiperazine derivatives in directive to explore the anticancer activity. Anticancer activity showing results discovered that these were the most active compounds in the series. Cisplatin was used as reference drug [25].

\subsubsection{Anti- viral activity}

Michele Tonelli synthesized seventy-six 2-phenyl benzimidazole derivatives and estimated for cytotoxicity and anti-viral activity compared to a panel of RNA and DNA viruses. Compound ([5,6-dichloro-2-(4-nitrophenyl) benzimidazole]) showed a high action resulting stronger than reference drugs smycophenolic acid and 6-azauridine [26].

\subsubsection{Antileishmanial activity}

Kalpana Bhandari created a sequence of substituted aryloxy alkyl and aryloxy aryl alkyl imidazole and estimated in vitro as antileishmanial against Leshmania Donovani. Between all compounds exhibited 94-100\% inhibition [27].

For the Triazoles and its derivatives possess a great importance in medicinal chemistry and can be used for the synthesis of numerous heterocyclic compounds with different biological activities. 1, 2, 4-triazole derivatives exhibit wide range of biological activities including:

Antibacterial [28, 29], Anti-fungal [30,31], Anti-tumour [32], Anti-inflammatory [33], Antitubercular [34], Hypogly caemic, Antidepressant, Anti convulsant, Anticancer, Antimalarial, Antiviral, Anti-proliferative, Analgesic [35].

\section{Conclusions}

Based on a different writing overview, azoles derive display different activity versus antimicrobial, anti-inflammatory, analgesic, Antitubercular, anticancer etc.

The potential enhancements in the movement can be additionally accomplished by slight alterations in the substituents on the fundamental imidazole nucleus. Possessing structural likeness with histidine imidazole compound can connect with protein molecules facility compared to some other heterocyclic moieties. 
Different current new drugs advancements in imidazole and triazoles derivatives demonstrate better impact and less harmfulness and toxicity. And based on some literature in the urodynamic assessment of detrusor and sphincter dysfunction, actually is a simple, however practical classification of the so-called neuropathic bladder is presented. It has demonstrated to be helpful and valuable in clinical practice to identify hazard factors and to design and proposal treatment techniques.

Many advances have been made in antifungal therapy over the last three decades. Itraconazole and fluconazole, two investigational triazole agents, are the most recent additions to the list of antifungal drugs. Review has focused primarily on their antifungal drugs and favorable pharmacologic properties, and spectra of activity against a broad range of systemic pathogens.

Ongoing and future clinical trials will more clearly define the specific roles of itraconazole and fluconazole in the treatment of systemic mycoses.

Finally, the reason for the utilization of these new therapeutic estimates stays sufficient essential consideration during the spinal shock stage and keeping away from the disease, bladder over distension, and urethral harm. Additionally, likewise with these new restorative methodologies, detrusor and sphincter dysfunction in these patients won't stay in a static state and practical and morphological changes may happen whenever, making long-lasting urological care obligatory.

\section{References}

[1] Anaissie E., Hachem R., Tin K.-U.-C., Stephens L. C., Bodey G. P. Experimental hematogenous candidiasis caused by Candida Krusei and Candida Albicans: species differences in pathogenicity. Infection and Immunity, Vol. 61, Issue 4, 1993, p. 1268-1271.

[2] Arthur M., Reynolds P., Courvalin P. Glycopeptide resistance in enterococci. Trends in Microbiology, Vol. 21, Issue 4, 1996, p. 401-407.

[3] Schappert S. M. National ambulatory medical care survey: 1992 summary. Advanced data from vital and health statistics. No. 253. Hyattsville, Md.: National Center for Health Statistics, 1994. (DHHS publication no. (PHS) 94-1250).

[4] Patton J. P., Nash D. B., Abrutyn E. Urinary tract infection: economic considerations. Medical Clinics of North America, Vol. 75, Issue 2, 1991, p. 495-513.

[5] Anaissie E. J., Bodey G. P. Nosocomial fungal infections. Old problems and new challenges. Infectious Disease Clinics of North America, Vol. 3, Issue 4, 1989, p. 867-882.

[6] Wey S. B., Mori M., Pfaller M., Woolson R. F., Wenzel R. P. Hospital-acquired candidemia. The attributable mortality and excess length of stay. Archives of Internal Medicine, Vol. 148, Issue 12, 1988, p. 2642-2645.

[7] Williams D. A., Lemke T. L. Foye's Principles of Medicinal Chemistry. Lippincott Williams and Wilkins, 2002.

[8] Pandeya Nath S. N. A Text Book of Medicinal Chemistry. SG publisher, 2004.

[9] Singh H., Kapoor V. K. Medicinal and Pharmaceutical Chemistry. Vallabh Prakashan, Delhi, 1996.

[10] Lednicer D., Mitscher L. A. In Organic Chemistry of Drug Synthesis. Wiley Interscience New York, 1997, p. 226.

[11] Katritzky A. R., Rees C. W. Comprehensive Heterocyclic Chemistry. Elsevier Science, Vol. 5, 1984, p. 469-498.

[12] Gilchrist T. L. Heterocyclic Chemistry. The Bath Press, 1985.

[13] Emami S., Foroumadi A., Falahati M., Lotfali E., Rajabalian S., Ahmed Ebrahimi D. S., Farahyarc S., Shafiee A. 2-Hydroxyphenacyl azoles and related azolium derivatives as antifungal agents. Bioorganic and Medicinal Chemistry Letters, Vol. 18, 2008, p. 141-146.

[14] Ujjinamatada R. K., Baier A., Borowski P., Hosmane Bioorg R. S. An analogue of AICAR with dual inhibitory activity against WNV and HCV NTPase/helicase: Synthesis and in vitro screening of 4-carbamoyl-5-(4,6-diamino-2,5-dihydro-1,3,5-triazin-2-yl)imidazole-1- $\beta$-d-ribofuranoside.

Bioorganic and Medicinal Chemistry Letters, Vol. 17, 2007, p. 2285-2288.

[15] Armstong D. Problems in management of opportunistic fungal diseases. Reviews of Infectious Diseases, Vol. 11, 1989, p. 1591-1599. 
[16] Terrell C. L., Hermans P. E. Antifungal agents used for deep-seated mycotic infections. Mayo Clinic Proceedings, Vol. 62, 1987, p. 1116-1128.

[17] Anaissie E., Kontoyiannis D. P., Bodey G. P. Fusarial hyalohyphomycosis; clinical spectrum, prognosis and treatment. 30th Interscience Conference on Antimicrobial Agents and Chemotherapy, Atlanta, 1990.

[18] Greene S. I. Treatment of Fungal Infections in the Human Immunod Efficiency Virus-Infected Individual in: Antifungal Drug Therapy. Marcel Dekker, New York, 1990, p. 237-246.

[19] Ringel S. New antifungal agents for the systemic mycoses. Mycopathologia, Vol. 109, 1990, p. 75-87.

[20] Brendler C. H. B., Radebaugh L. C., Mohler J. L. Topical oxybutynin chloride (Ditropan) for relaxation of dysfunctional bladder. Journal of Urology, Vol. 139, Issue 4, 1988, p. 334.

[21] Brindley G. S., Polkey C. E., Rushton D. N., Cardo Z. O. L. Sacral anterior root stimulators for bladder control in paraplegia: the first 40 cases. Proceedings of the International Society 14th Annual Meeting, Plattner-Druck, Innsbruck, 1984, p. 53-54.

[22] Shingalapur R. V., Hosamani K. M., Keri R. S. Synthesis and evaluation of in vitro anti-microbial and anti-tubercular activity of 2-styryl benzimidazoles. European Journal of Medicinal Chemistry, Vol. 44, Issue 10, 2009, p. 4244-4248.

[23] Puratchikodya A., Doble M. Antinociceptive and anti-inflammatory activities and QSAR studies on 2-substituted-4, 5-diphenyl-1H-imidazoles Biorganic and medicinal chemistry. Bioorganic and Medicinal Chemistry, Vol. 15, Issue 1, 2007, p. 1083-1090.

[24] Hadizadeh F., Hosseinzadeh H., Sadat Motamed Shariaty V., Seifi M., Kazemi S. Synthesis and antidepressant activity of n-substituted imidazole-5-carboxamides in forced swimming test model. Iranian Journal of Pharmaceutical Research, Vol. 7, Issue 1, 2008, p. 29-33.

[25] Özkay Y., Isikdag I., Incesu Z., Akalın G. E. Synthesis of 2-substituted-N-[4-(1-methyl-4,5diphenyl-1H-imidazole-2-yl)phenyl] acetamide derivatives and evaluation of their anticancer activity. European Journal of Medicinal Chemistry, Vol. 45, Issue 8, 2010, p. 3320-3328.

[26] Tonelli M., Simone M., Tasso B., Novelli F., Boido V. Antiviral activity of benzimidazole derivatives. II. Antiviral activity of 2-phenylbenzimidazole derivatives. Bioorganic and Medicinal Chemistry, Vol. 18, Issue 8, 2010, p. 2937-2953.

[27] Bhandari K., Srinivas N., Marrapu V. K., Verma A., Srivastava S., Gupta S. Synthesis of substituted aryloxy alkyl and aryloxy aryl alkyl imidazoles as antileishmanial agents. Bioorganic and Medicinal Chemistry Letters, Vol. 20, Issue 1, 2009, p. 291-293.

[28] Varvarason A., Tantili Kakoulidou A., Siatra Papastasikoudi T., Tiligada E. Synthesis and biological evaluation of indole containing derivatives of thiosemicarbazide and their cyclic 1,2,4triazole and 1,3,4-thiadiazole analogs. Arzneim Forsch, Vol. 50, Issue 1, 2000, p. 48-54.

[29] Pintilie O., Profire L., Sunel V., Popa M., Pui A. Synthesis and antimicrobial activity of some new 1, 3, 4-thiadiazole and 1, 2, 4-triazole compounds having a D,L-methionine moiety. Molecules, Vol. 12, Issue 1, 2007, p. 103-113.

[30] Zan X. I., Lai L. H., Ji G. Y., Zhon Z. X. Synthesis, fungicidal activity, and 3D-QSAR of pyridazinone-substituted 1,3,4-oxadiazoles and 1,3,4-thiadiazoles. Journal of Agricultural and Food Chemistry, Vol. 50, Issue 12, 2002, p. 3757-3760.

[31] Chen H., Li Z., Han Y. Synthesis and fungicidal activity against Rhizoctonia solani of 2-alkyl (Alkylthio)-5-pyrazolyl-1,3,4-oxadiazoles (Thiadiazoles). Journal of Agricultural and Food Chemistry, Vol. 48, Issue 11, 2000, p. 5312-5315.

[32] Passannanti A., Diana P., Barraja P., Mingoia F., Lauria A., Cirrincione G. pyrrolo[2,3d] $[1,2,3]$ triazoles as potential antineoplastic agents. Heterocycles, Vol. 48, Issue 6, 1998, p. 1229-1235.

[33] Hosur M. S., Talwar R. Synthesis and antiinflammatory activity of 3-substituted-4-amino-5mercapto-4(h)-1, 2, 4-triazole. Indian Journal of Pharmaceutical Sciences, Vol. 55, 1993, p. 86.

[34] Mhasalkar M. Y., Shah M. H., Nikam S. T., Deliwda C. V. 4-Alkyl-5-aryl-4-H-1,2,4-triazole-3thiol as Hypoglycemic agents. Journal of Medicinal Chemistry, Vol. 13, Issue 4, 1970, p. 672-676.

[35] Mhasalkar M. Y., Shah M. H., Nikam S. T. Further studies in substituted 4 H -1, 2, 4-triazoles for possible hypoglycemic activity. Journal of Medicinal Chemistry, Vol. 14, Issue 3, 1971, p. 260-262. 